\title{
Cathodic Behaviour of Al-Ga Alloy in AQUEOUS SOLUTIONS
}

\author{
VisekrunA, A.; Pilic, Z.; MARTINOVIC, A. \& Miskovic, I.
}

Abstract: This study has examined the effect of different gallium contents in $5 \mathrm{~N} \mathrm{Al-Ga}$ and $99.8 \% \mathrm{Al}-\mathrm{Ga}$ alloys on the nature of the phenomenon that occurs in the interphase (alloy - solution) during cathodic polarisation at high cathode potentials. After cathodic polarisation, anodic current was traced vs. time in order to determine the quantity of charge necessary for oxidation of substances formed.

The open circuit potential (OCP) was also examined relative to time for different gallium contents in alloys at different $\mathrm{pH}$ values of the $\mathrm{NaCl}$ and $\mathrm{NaF}$ solution.

Key words: cathodic polarisation, super-pure aluminium, technical aluminium, Al-Ga alloy
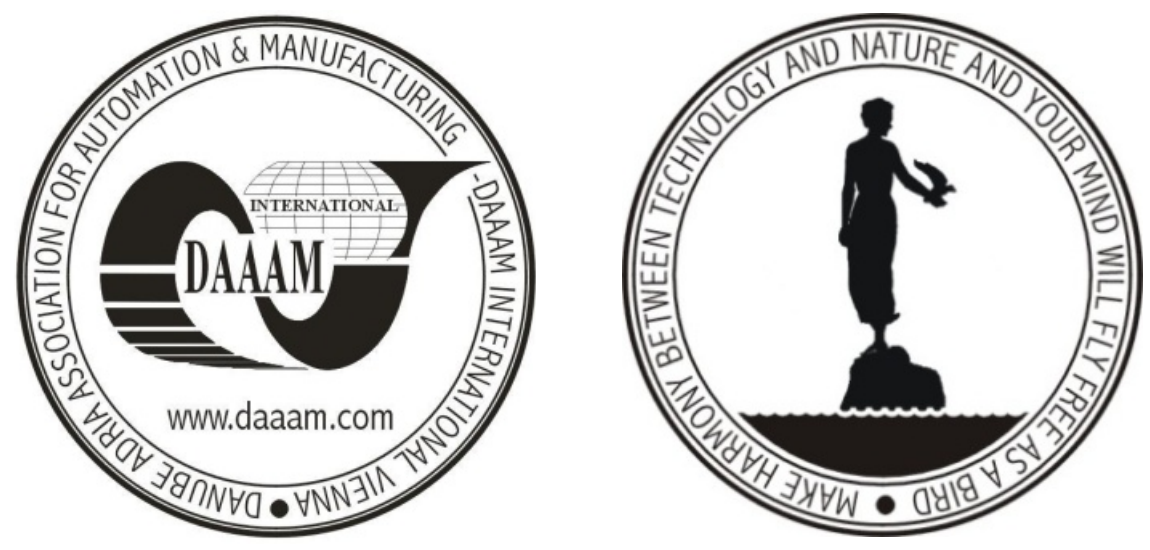

Authors' data: Dr. sc. Visekruna, A[ntonija]; Dr. sc. Pilic, Z[ora]; Mr.sc. Martinovic, A[nita]; Miskovic, I[vana], Faculty of science University of Mostar, Matice hrvatske bb, 88000 Mostar, Bosnia and Herzegovina; antonija.visekruna@sve-mo.ba, zora.pilic@sve-mo.ba, anita.martinovic@sve-mo.ba, ivana.miskovic@sve-mo.ba

This Publication has to be referred as: Visekruna, A[ntonija]; Pilic, Z[ora]; Martinovic, A[nita] \& Miskovic, I[vana] (2009). Cathodic Behaviour of Al-Ga Alloy in Aqueous Solutions, Chapter 42 in DAAAM International Scientific Book 2009, pp. 405-418, B. Katalinic (Ed.), Published by DAAAM International, ISBN 978-3901509-69-8, ISSN 1726-9687, Vienna, Austria

DOI: $10.2507 /$ daaam.scibook.2009.42 